\title{
Electronic structure of mixed-valence silver oxide AgO from hybrid density-functional theory
}

\author{
Jeremy P. Allen, David O. Scanlon, ${ }^{*}$ and Graeme W. Watson ${ }^{\dagger}$ \\ School of Chemistry, Trinity College Dublin, Dublin 2, Ireland \\ (Received 3 December 2009; revised manuscript received 2 March 2010; published 29 April 2010)
}

\begin{abstract}
Mixed-valence $\mathrm{AgO}$ has attracted attention due to its utility in battery technologies. Despite this, a nanoscopic understanding of its electronic structure has been lacking and there has been considerable controversy about the formal oxidation states of silver in the system. In this Rapid Communication we study the electronic structure of $\mathrm{AgO}$ using density functional theory:generalized gradient approximation (GGA) and a screened hybrid density functional (HSE). GGA is found to be unable to model the mixed valence of the material, resulting in an $\mathrm{Ag}^{\mathrm{II}} \mathrm{O}$ symmetric structure. We show conclusively using HSE that the oxidation states of silver in $\mathrm{AgO}$ are $\mathrm{Ag}^{\mathrm{I}}$ and $\mathrm{Ag}^{\mathrm{III}}$, and not $\mathrm{Ag}^{\mathrm{I}}$ and $\mathrm{Ag}^{\mathrm{II}}$ with holes on neighboring oxygen ions as had previously been predicted.
\end{abstract}

DOI: 10.1103/PhysRevB.81.161103

PACS number(s): 71.15.Mb, 71.20.Nr

\section{INTRODUCTION}

Mixed-valence silver oxide $\mathrm{AgO}$ (also known as $\mathrm{Ag}_{4} \mathrm{O}_{4}$ ) is an $n$-type semiconductor which has primary commercial applications in battery technology, where it is used with $\mathrm{Ag}_{2} \mathrm{O}$ in $\mathrm{Zn}$ silver-oxide batteries. ${ }^{1-3}$ It has also gained interest for possessing bacteriostatic properties, ${ }^{4,5}$ and has been tested for applications in the treatment and cure of dermatological skin conditions. ${ }^{6}$ Although not as widely studied as $\mathrm{Ag}_{2} \mathrm{O}$, several structural and spectroscopic studies have been carried out on $\mathrm{AgO}$ in an effort to elucidate the geometry and electronic structure of the material. ${ }^{7-12}$

$\mathrm{AgO}$ crystallizes in a monoclinic structure (space group $\left.P 12_{1} / c 1\right)$ with Ag ions in two distinct coordination environments. ${ }^{7}$ Neutron-diffraction experiments have indicated that it is composed of linearly coordinated Ag ions (denoted $\mathrm{Ag}^{\text {lin }}$ ) and $\mathrm{Ag}$ ions in a slightly distorted square planar coordination with four oxygens ${ }^{8}$ (denoted $\mathrm{Ag}^{\mathrm{sq}}$ ), as shown in Fig. 1. It has been suggested that $\mathrm{Ag}^{\text {lin }}$ can be attributed to $\mathrm{Ag}$ with an oxidation state of $+1\left(\mathrm{Ag}^{\mathrm{I}}\right)$ and that $\mathrm{Ag}^{\mathrm{sq}}$ can be attributed to $\mathrm{Ag}$ with an oxidation state of +3 $\left(\mathrm{Ag}{ }^{\mathrm{III}}\right) .{ }^{8} \mathrm{AgO}$ has been reported to be diamagnetic, ${ }^{9}$ which is consistent with spin paired configurations of linearly coordinated $4 d^{10} \mathrm{Ag}^{\mathrm{I}}$, and square planar $4 d^{8} \mathrm{Ag}^{\mathrm{III}} .{ }^{13}$ The coordination environments around the $\mathrm{Ag}$ ions in $\mathrm{AgO}$ are also consistent with the coordination environments of $\mathrm{Ag}^{\mathrm{I}}$ in $\mathrm{Ag}_{2} \mathrm{O}$ (Ref. 14) and $\mathrm{Ag}^{\mathrm{III}}$ in $\mathrm{Ag}_{2} \mathrm{O}_{3} .{ }^{15}$

Early theoretical calculations carried out using localdensity approximation (LDA) within the full-potential linearized augmented-plane-wave method have challenged the view that $\mathrm{Ag}^{\mathrm{I}}$ and $\mathrm{Ag}^{\mathrm{III}}$ are present in $\mathrm{AgO} .{ }^{12}$ The authors predicted that the cation valences are $\mathrm{Ag}^{\mathrm{I}}$ and $\mathrm{Ag}^{\mathrm{II}}$ with holes present on the oxygen ions. ${ }^{12}$ This oxygen-hole theory was postulated due to the small $\mathrm{O} p$-Ag $d$ energy separation. ${ }^{12}$ $\mathrm{X}$-ray photoelectron spectroscopy (XPS) studies of $\mathrm{AgO}$ have reported two $\mathrm{O} 1 s$ core levels despite the fact that only one inequivalent oxygen site exists in the structure. ${ }^{10}$ The presence of these two core levels is attributed to oxygen in -2 and -1 valences, ${ }^{10}$ consistent with the theory of Park et $a l .{ }^{12}$ Another study of AgO using XPS and electron energyloss spectroscopy cast doubt on the presence of $\mathrm{Ag}^{\mathrm{III}}$ in $\mathrm{AgO}$. They stated that it was difficult to understand how $\mathrm{Ag}^{\mathrm{III}}$ forms due to the fact that no other Ag compound with the $\mathrm{Ag}^{\mathrm{III}}$ valence had been reported, ${ }^{11}$ despite the fact that the crystal structure of $\mathrm{Ag}_{2} \mathrm{O}_{3}$ had been reported five years earlier. $^{15}$

The presence of two O $1 s$ core-level peaks had been previously noted in other photoemission spectroscopy (PES) studies of $\mathrm{AgO}$, but has been attributed to $\mathrm{Ag}$ carbonates or bicarbonates, hydroxyl groups, and adsorbed water, and not to oxygen holes. ${ }^{11}$ Carbonate impurities are probably present in all AgO samples as their removal by sample calcination has been reported to be very difficult due to $\mathrm{Ag}_{2} \mathrm{CO}_{3}$ being more thermally stable than AgO ${ }^{16}$ Contrary to the PES studies of Bielmann et al. ${ }^{10}$ and Hoflund et al., ${ }^{11}$ the XPS and $\mathrm{X}$-ray adsorption spectroscopy study by Lützenkirchen-Hecht and Strehblow ${ }^{17}$ support the theory that the Ag valences in $\mathrm{AgO}$ are $\mathrm{Ag}^{\mathrm{I}}$ and $\mathrm{Ag}^{\mathrm{III}}$. An X-ray absorption near-edge structure (XANES) study has also supported the $\mathrm{Ag}^{\mathrm{I}} / \mathrm{Ag}^{\mathrm{III}}$ theory. ${ }^{18}$ The authors considered both $\mathrm{Ag} L_{1}$ and $L_{3}$ XANES spectra for a range of binary oxides and silver containing compounds with the trends in the data clearly supporting an $\mathrm{Ag}^{\mathrm{I}}$ and $\mathrm{Ag}^{\mathrm{III}}$ mixed oxidation state rather than $\mathrm{Ag}^{\mathrm{I}}$ and $\mathrm{Ag}^{\mathrm{II}}$.

In this Rapid Communication we investigate the geometry and electronic structure of $\mathrm{AgO}$ using state of the art firstprinciples approaches. We show: (i) generalized gradient approximation (GGA) is incapable of modeling the mixedvalence structure of $\mathrm{AgO}$, predicting a structure with equivalent Ag sites, (ii) hybrid density functional (HSE) results in a structure consistent with experiment with two distinct $\mathrm{Ag}$ coordinations, and (iii) Bader charge analysis and comparison with $\mathrm{Ag}_{2} \mathrm{O}$ and $\mathrm{Ag}_{2} \mathrm{O}_{3}$ indicates that $\mathrm{Ag}^{\mathrm{I}}$ and $\mathrm{Ag}^{\text {III }}$ are present in $\mathrm{AgO}$.

All our DFT calculations were performed using the VASP code $^{19}$ with the projector augmented wave approach. ${ }^{20}$ The calculations were performed using both the GGA of Perdew, Burke, and Ernzerhof (PBE) (Ref. 21) and the hybrid functional as proposed by Heyd et al. ${ }^{22}$ with the inclusion of spin polarization in all calculations. Difficulties in evaluating the Fock exchange in a real-space formalism are caused by the slow decay of the exchange interaction with distance. In the HSE06 hybrid functional approach, this problem is addressed by separating the description of the exchange interaction into long- and short-range parts. ${ }^{22}$ Thus, a percentage $(\alpha=25 \%)$ of exact nonlocal Fock exchange is added to the 


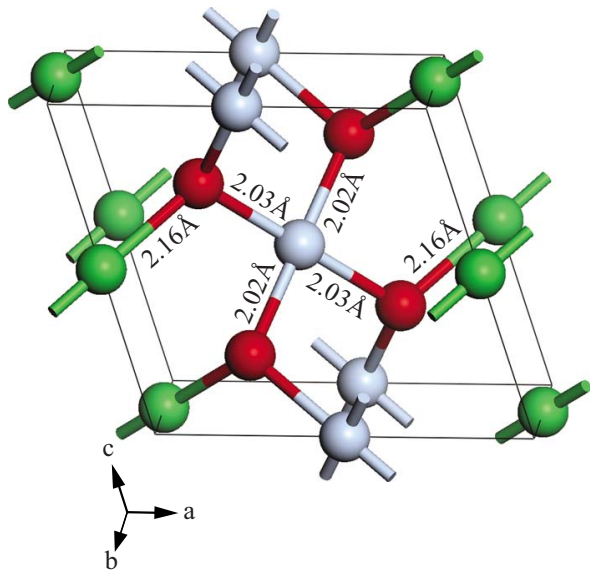

FIG. 1. (Color online) (a) Experimental crystal structure of AgO (Ref. 7). Green (medium gray) spheres denote linearly coordinated $\mathrm{Ag}^{\text {lin }}$, light blue (light gray) spheres denote square planar coordinated $\mathrm{Ag}^{\mathrm{sq}}$, and red (dark gray) spheres represent oxygen.

PBE functional and a screening of $\omega=0.11 \mathrm{bohr}^{-1}$ is applied to partition the Coulomb potential into long-range (LR) and short-range (SR) terms. Thus the exchange and correlation terms are

$$
E_{x c}^{\mathrm{HSE}}(\omega)=E_{x}^{\mathrm{HSE}, \mathrm{SR}}+E_{x}^{\mathrm{PBE}, \mathrm{LR}}+E_{c}^{\mathrm{PBE}},
$$

where

$$
E_{x}^{\mathrm{HSE}, \mathrm{SR}}=\frac{1}{4} E_{x}^{\mathrm{Fock}, \mathrm{SR}}+\frac{3}{4} E_{x}^{\mathrm{PBE}, \mathrm{SR}} .
$$

Hartree-Fock (HF) and PBE exchange are therefore only mixed in the SR part with the LR exchange interactions being represented by the PBE functional. ${ }^{22} \mathrm{HSE}$ has been shown repeatedly to produce structural-data and band-gap descriptions that are more accurate than LDA/GGA and meta-GGA data. ${ }^{23-31}$ Cutoffs of $500 \mathrm{eV}$ were used for the GGA and $400 \mathrm{eV}$ was used for the more computationally expensive HSE calculations. Gamma centered $k$-point meshes of $4 \times 6 \times 4$ were found to be sufficient for all methods. Calculations were deemed to be converged when the forces on all the atoms were less than $0.01 \mathrm{eV} \mathrm{A}^{-1}$.

The GGA and HSE calculated structural parameters for $\mathrm{AgO}$ are presented in Table I. It is clear that minimization of

TABLE I. Lattice constants, interatomic distances, and angles for $\mathrm{AgO}$, calculated using GGA and HSE methods, and the corresponding experimental values. All distances are in $\AA$ and angles are in degrees.

\begin{tabular}{lcccc}
\hline \hline & GGA & HSE & HF & Expt. (Ref. 7) \\
\hline$a$ & 4.74 & 5.97 & 5.96 & 5.86 \\
$b$ & 4.62 & 3.55 & 3.69 & 3.48 \\
$c$ & 5.60 & 5.57 & 5.53 & 5.50 \\
Ag $^{\text {lin_O }}$ & 2.17 & 2.15 & 2.31 & 2.16 \\
Ag $^{\text {sq-O }}$ & 2.17 & $2.01,2.02$ & $1.99,1.99$ & $2.02,2.03$ \\
Angle $(\beta)$ & 90.31 & 107.33 & 102.85 & 107.56 \\
\hline \hline
\end{tabular}

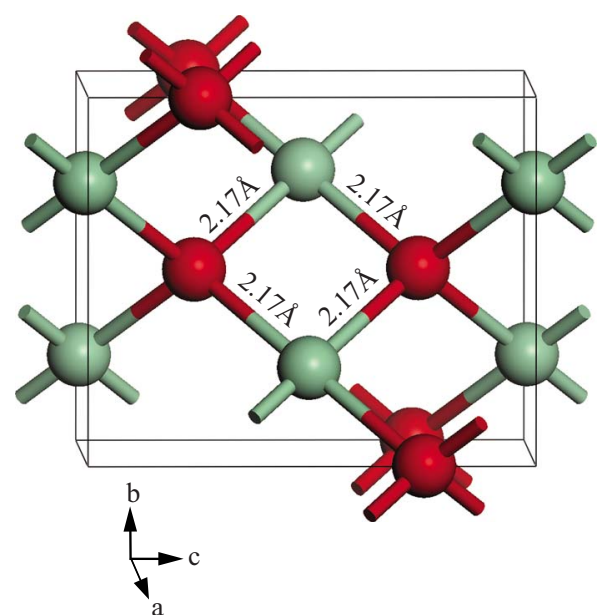

FIG. 2. (Color online) GGA symmetric structure of $\mathrm{AgO}$ with equivalent $\mathrm{Ag}$ sites. The light green (light gray) spheres represent the $\mathrm{Ag}$ and red (dark gray) spheres represent $\mathrm{O}$ ions.

the $\mathrm{AgO}$ structure using GGA yields a structure in disagreement with the experimentally known crystal structure. GGA predicts a structure with only one inequivalent $\mathrm{Ag}$ site, which is fourfold coordinated with Ag-O bond lengths of $2.17 \AA$, Fig. 2. On closer inspection, this bonding environment is very similar to that seen in $\mathrm{CuO}$, where $\mathrm{Cu}^{\mathrm{II}}$ is the only cation present. ${ }^{32}$ Thus it seems that GGA is unable to relax to the experimental structure with two different Ag sites but rather predicts an $\mathrm{AgO}$ structure with equivalent $\mathrm{Ag}$ (presumably $\mathrm{Ag}^{\mathrm{II}}$ ) sites. The band structure for the GGA AgO structure with equivalent $\mathrm{Ag}$ coordinations indicates that the material is metallic (Fig. 3), which is at variance with the experimentally known semiconducting nature. . $^{33,34}$

Considering the fact that our GGA calculations predict $\mathrm{AgO}$ to be a metallic material with equivalent Ag coordinations, it is puzzling that the LDA calculations of Park et al. ${ }^{12}$ yielded two distinct $\mathrm{Ag}$ coordinations with a small indirect band gap of $0.03 \mathrm{eV}$. We have calculated an unrelaxed GGA bandstructure for the material, which yielded a small indirect
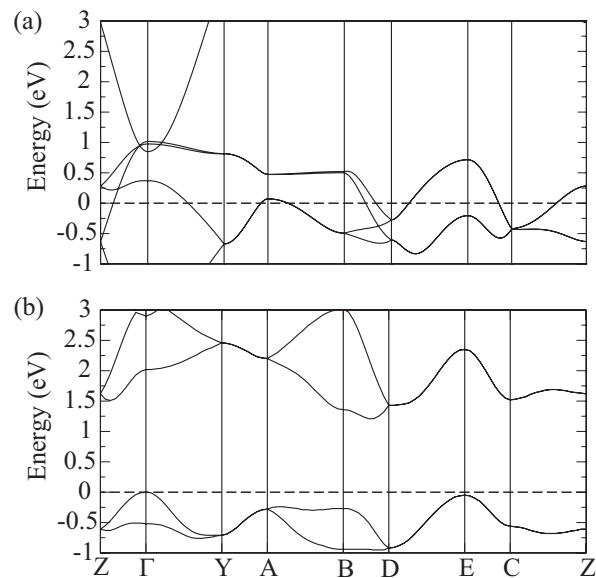

FIG. 3. (a) GGA and (b) HSE calculated band structures for 


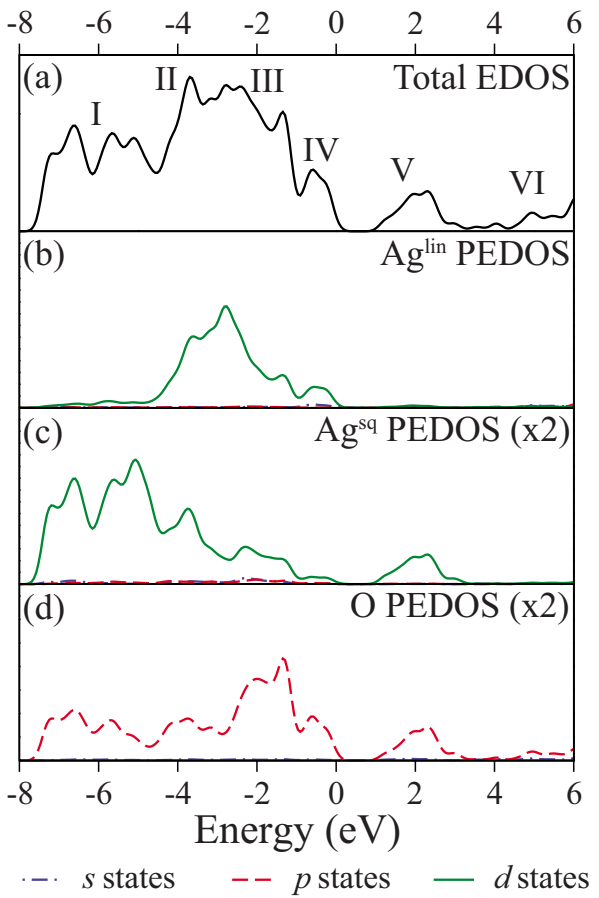

FIG. 4. (Color online) Electronic density of states for AgO. (a) Total EDOS, (b) $\mathrm{Ag}^{\text {lin }}$ PEDOS, (c) $\mathrm{Ag}^{\text {sq }}$ PEDOS, and (d) O PEDOS, as calculated using the HSE method. For (b)-(d), the $s, p$, and $d$ states are colored blue (dots dashes), red (dashes), and green (solid), respectively.

band gap of $0.2 \mathrm{eV}$. This indicates that the previous LDA calculations did not involve ionic relaxation. ${ }^{12}$

Minimization of $\mathrm{AgO}$ using $\mathrm{HSE}$ yields a structure very similar to the experimental structure. The lattice vectors are all within $<1.9 \%$ of the experimental values (Table I) and the differing coordination around both Ag sites is maintained. We have also examined the structure with full HF and find a similar result to the HSE approach, albeit with a slightly expanded lattice. Analysis of the HSE band structure reveals that the valence band (VB) maximum appears at $\Gamma$ with the conduction-band minimum occurring on the line from $\mathrm{B}$ to D, Fig. 3. Thus $\mathrm{AgO}$ has an indirect band gap of $1.2 \mathrm{eV}$, and a smallest direct band gap of $1.6 \mathrm{eV}$ which occurs between $\mathrm{B}$ and $\mathrm{D}$, which are consistent with the experimentally measured optical band gaps of $1-1.1 \mathrm{eV} .^{33,34}$

Analysis of the partial electronic densities of states (PEDOS) reveals that the Ag positions have considerably different features, Fig. 4. The PEDOS of the $\mathrm{Ag}^{\text {lin }}$ site reveals that the $\mathrm{VB}$ is dominated by $\mathrm{Ag} 4 d$ states with a central peak at $\sim-3.5 \mathrm{eV}$. This is consistent with PEDOS previously calculated for $\mathrm{Ag}_{2} \mathrm{O}$, where $\mathrm{Ag}$ is also in the +1 oxidation state. ${ }^{35}$ For the $\mathrm{Ag}^{\mathrm{sq}}$ site, the PEDOS is very different. The $\mathrm{Ag} 4 \mathrm{~d}$ states straddle the entire VB with two large peaks situated at $\sim-7$ and $\sim-4.5 \mathrm{eV}$. States with Ag $4 d$ character can also be seen at the bottom of the conduction band, which is consistent with $\mathrm{Ag}$ having a valence higher than $\mathrm{Ag}$ lin. Indeed the $\mathrm{Ag}^{\text {sq }}$ PEDOS for $\mathrm{AgO}$ is consistent with the PEDOS for $\mathrm{Ag}^{\mathrm{III}}$ in $\mathrm{Ag}_{2} \mathrm{O}_{3} \cdot{ }^{36}$

To understand the oxidation states present in $\mathrm{AgO}$, it is instructive to analyze the Bader $^{37}$ charges of the material, and compare them to the charges on $\mathrm{Ag}$ in $\mathrm{Ag}_{2} \mathrm{O}$ and $\mathrm{Ag}_{2} \mathrm{O}_{3}$.
TABLE II. Bader charges for $\mathrm{Ag}$ and $\mathrm{O}$ in $\mathrm{Ag}_{2} \mathrm{O}, \mathrm{Ag}_{2} \mathrm{O}_{3}$, and $\mathrm{AgO}$. The charge for $\mathrm{O}_{1}$ in the $\mathrm{Ag}_{2} \mathrm{O}_{3}$ structure refers to an average over oxygen atoms $\mathrm{O}_{1}, \mathrm{O}_{1 a}$, and $\mathrm{O}_{1 b}$ (Ref. 15). Quoted values are HSE and GGA values are in parenthesis.

\begin{tabular}{lcc}
\hline \hline Structure & Ag charge & O charge \\
\hline $\mathrm{Ag}_{2} \mathrm{O}$ & $+0.52(+0.47)$ & $-1.04(-0.94)$ \\
$\mathrm{Ag}_{2} \mathrm{O}_{3}$ & $+1.23(+1.10)$ & $\mathrm{O}_{1}:-0.85(-0.74)$ \\
& & $\mathrm{O}_{2}:-0.77(-0.72)$ \\
$\mathrm{AgO}$ & $\mathrm{Ag}^{\text {lin. }}:+0.65(+0.83)$ & $-0.91(-0.83)$ \\
& $\mathrm{Ag}^{\text {sq: }}+1.17(+0.83)$ & \\
\hline \hline
\end{tabular}

The corresponding GGA and HSE computed Bader charges are listed in Table II. The HSE charges for $\mathrm{Ag}^{\mathrm{sq}}$ in $\mathrm{AgO}$ are very similar to those of $\mathrm{Ag}^{\mathrm{III}}$ in $\mathrm{Ag}_{2} \mathrm{O}_{3}$. Similarly the charges of $\mathrm{Ag}^{\mathrm{I}}$ in $\mathrm{Ag}_{2} \mathrm{O}$ are consistent with those of $\mathrm{Ag}^{\text {lin }}$ in our HSE minimized $\mathrm{AgO}$. It is also clear that the GGA charges for $\mathrm{AgO}$ are at variance with those for $\mathrm{Ag}_{2} \mathrm{O}$ and $\mathrm{Ag}_{2} \mathrm{O}_{3}$. The Bader charge analysis therefore strongly supports the suggestion that the $\mathrm{Ag}$ is present as both +1 and +3 oxidation states. It also indicates that the oxidation state of $\mathrm{Ag}$ in the GGA minimized $\mathrm{AgO}$ structure is between that of $\mathrm{Ag}^{\mathrm{I}}$ and $\mathrm{Ag}^{\mathrm{III}}$, indicating that GGA has predicted an $\mathrm{Ag}^{\mathrm{II}} \mathrm{O}$ structure, similar to $\mathrm{CuO}$.

The reported diamagnetism of the $\mathrm{AgO}$ structure $^{9}$ is also not consistent with the $\mathrm{Ag}^{\mathrm{I}} / \mathrm{Ag}^{\mathrm{II}}$ theory, as $\mathrm{Ag}^{\mathrm{II}}$ would be formally $4 d^{9}$, and thus have a magnetic moment similar to $\mathrm{Cu}^{\mathrm{II}}$ in $\mathrm{CuO}$. It is widely known that $\mathrm{CuO}$ is an antiferromagnetic semiconductor. ${ }^{38}$ Therefore the absence of magnetism in $\mathrm{AgO}$ is a valid indicator that a valence of $\mathrm{Ag}^{\mathrm{II}}$ is most likely not present. Similarly the oxygen hole argument is highly questionable. In most oxides with $\mathrm{O} 2 p$ dominated VBs, $p$-type defect formation results in localized oxygen holes (polarons), bound to strong lattice distortions. ${ }^{39,40}$ There has been no evidence presented for strong structural distortions in $\mathrm{AgO}$. In addition to this, the presence of $\mathrm{Ag}^{\mathrm{I}}$ in the $\mathrm{AgO}$ system (which is not in doubt), would mean that any holes formed would most likely reside on the Ag ions, similar to hole formation in $\mathrm{Cu}_{2} \mathrm{O} \cdot{ }^{27,41} \mathrm{In}$ fact, alloying wide band gap oxides with formally $d^{10}\left(\mathrm{Ag}^{\mathrm{I}}, \mathrm{Cu}^{\mathrm{I}}\right)$ metal oxides is currently the most effective way to form $p$-type transparent conducting oxides, in an effort to stop the formation of localized oxygen holes that limit conductivity. ${ }^{28,42}$ Thus the formation of $\mathrm{Ag}^{\mathrm{II}}$ with synergistic oxygen holes in $\mathrm{AgO}$ is chemically unlikely.

The failure of GGA to describe the mixed valence of $\mathrm{AgO}$ is not surprising, as GGA has been shown to fail to capture the structure, valence $\left(\mathrm{Bi}^{\mathrm{III}}\right.$ and $\left.\mathrm{Bi}^{\mathrm{V}}\right)$ or semiconducting properties of $\mathrm{BaBiO}_{3}{ }^{43,44} \mathrm{An}$ explanation for this problematic failure of GGA is that standard semilocal exchangecorrelation functionals, such as LDA or GGA predict a too small charge disproportionation, resulting in a metallic description of known semiconductors. ${ }^{45}$

In conclusion we have carried out GGA and state of the art HSE calculations on mixed-valence AgO. Minimization 
of the AgO structure with GGA highlighted the abject failure of GGA/LDA methods at handling materials with a cation that displays multiple oxidation states. The HSE calculations have captured the different coordinations of the Ag ions. Analysis of the HSE calculated EDOS/PEDOS and Bader charges point to the fact that the $\mathrm{Ag}$ valences present are in fact $\mathrm{Ag}^{\mathrm{I}}$ and $\mathrm{Ag}^{\mathrm{III}}$, and not $\mathrm{Ag}^{\mathrm{I}}$ and $\mathrm{Ag}^{\mathrm{II}}$ with synergistic oxygen holes.

\section{ACKNOWLEDGMENTS}

This work was supported by Science Foundation Ireland through the Principal Investigators program (PI Grants No. 06/IN.1/I92 and No. 06/IN.1/I92/EC07). Calculations were performed on the IITAC and Lonsdale supercomputers as maintained by TCHPC, and the Stokes supercomputer as maintained by ICHEC. *scanloda@tcd.ie

† watsong@tcd.ie

${ }^{1}$ D. F. Smith and J. A. Gucinski, J. Power Sources 80, 66 (1999).

${ }^{2}$ D. F. Smith and C. Brown, J. Power Sources 96, 121 (2001).

${ }^{3}$ J. Pan, Y. Sun, Z. Wang, P. Wan, X. Liu, and M. Fan, J. Mater. Chem. 17, 4820 (2007).

${ }^{4}$ D. Dellasega, A. Facibeni, F. Di Fonzo, M. Bogana, A. Polissi, C. Conti, C. Ducati, C. S. Casari, A. Li Bassi, and C. E. Bottani, Nanotech. 19, 475602 (2008).

${ }^{5}$ D. Dellasega, A. Facibeni, F. Di Fonzo, V. Russo, C. Conti, C. Ducati, C. S. Casari, A. Li Bassi, and C. E. Bottani, Appl. Surf. Science 255, 5248 (2009).

${ }^{6}$ M. S. Antelman, US Patent No. 5.211.855 (18 May 1993).

${ }^{7}$ M. Jansen and P. Fischer, J. Less-Common Met. 137, 123 (1988).

${ }^{8}$ V. Scatturin, P. L. Bellon, and A. J. Salkind, J. Electrochem. Soc. 108, 819 (1961).

${ }^{9}$ A. B. Neiding and I. A. K. Kazarnovski, Dokl. Akad. Nauk SSSR 78, 713 (1951).

${ }^{10}$ M. Bielmann, P. Schwaller, P. Ruffieux, O. Gröning, L. Schlapbach, and P. Gröning, Phys. Rev. B 65, 235431 (2002).

${ }^{11}$ G. B. Hoflund, Z. F. Hazos, and G. N. Salaita, Phys. Rev. B 62, 11126 (2000).

${ }^{12}$ K.-T. Park, D. L. Novikov, V. A. Gubanov, and A. J. Freeman, Phys. Rev. B 49, 4425 (1994).

${ }^{13}$ C. Housecroft and A. G. Sharpe, Inorganic Chemistry (Pearson, Harlow, UK, 2008), p. 3000

${ }^{14}$ P. Norby, R. Dinnebier, and A. N. Fitch, Inorg. Chem. 41, 3628 (2002).

${ }^{15}$ B. Standke and M. Jansen, Angew. Chem., Int. Ed. Engl. 24, 118 (1985).

${ }^{16}$ G. I. N. Waterhouse, G. A. Bowmaker, and J. B. Metson, Phys. Chem. Chem. Phys. 3, 3838 (2001).

${ }^{17}$ D. Lützenkirchen-Hecht and H.-H. Strehblow, Surf. Interface Anal. 41, 820 (2009).

${ }^{18}$ P. Behrens, S. Aßmann, U. Bilow, C. Linke, and M. Jansen, Z. Anorg. Allg. Chem. 625, 111 (1999).

${ }^{19}$ G. Kresse and J. Furthmüller, Phys. Rev. B 54, 11169 (1996).

${ }^{20}$ G. Kresse and D. Joubert, Phys. Rev. B 59, 1758 (1999).

${ }^{21}$ J. P. Perdew, K. Burke, and M. Ernzerhof, Phys. Rev. Lett. 77, 3865 (1996).

${ }^{22}$ S. Heyd, G. E. Scuseria, and M. Ernzerhof, J. Chem. Phys. 118,
8207 (2003).

${ }^{23}$ J. Heyd and G. E. Scuseria, J. Chem. Phys. 121, 1187 (2004).

${ }^{24}$ J. Heyd, J. E. Peralta, G. E. Scuseria, and R. L. Martin, J. Chem. Phys. 123, 174101 (2005).

${ }^{25}$ A. Walsh, J. L. F. Da Silva, Y. Yan, M. M. Al-Jassim, and S. H. Wei, Phys. Rev. B 79, 073105 (2009).

${ }^{26}$ S. Chen, Z. G. Gong, A. Walsh, and S. H. Wei, Appl Phys. Lett. 94, 041903 (2009).

${ }^{27}$ D. O. Scanlon, B. J. Morgan, G. W. Watson, and A. Walsh, Phys. Rev. Lett. 103, 096405 (2009).

${ }^{28}$ D. O. Scanlon and G. W. Watson, Chem. Mater. 21, 5435 (2009).

${ }^{29}$ D. O. Scanlon, A. Walsh, and G. W. Watson, Chem Mater. 21, 4568 (2009).

${ }^{30}$ M. Marsman, J. Paier, A. Stroppa, and G. Kresse, J. Phys.: Condens. Matter 20, 064201 (2008).

${ }^{31}$ A. Stroppa and G. Kresse, Phys. Rev. B 79, 201201(R) (2009).

${ }^{32}$ A. Stergiou, I. Kerasiotis, and C. Stergiou, J. Optoelectron. Adv. Mater. 9, 1772 (2007).

${ }^{33}$ B. E. Breyfogle, C. J. Hung, M. G. Shumsky, and J. A. Switzer, J. Electrochem. Soc. 143, 2741 (1996).

${ }^{34}$ N. Ravi Chandra Raju, K. Jagadeesh Kumar, and A. Subrahmanyam, J. Phys. D. 42, 135411 (2009).

${ }^{35}$ M. T. Czyżyk, R. A. de Groot, G. Dalba, P. Fornasini, A. Kisiel, F. Rocca, and E. Burattini, Phys. Rev. B 39, 9831 (1989).

${ }^{36}$ J. P. Allen, D. O. Scanlon, and G. W. Watson (unpublished).

${ }^{37}$ W. Tang, E. Sanville, and G. Henkelman, J. Phys.: Condens. Matter 21, 084204 (2009).

${ }^{38}$ X. Q. Chen, C. L. Fu, C. Franchini, and R. Podloucky, Phys. Rev. B 80, 094527 (2009).

${ }^{39}$ O. F. Schirmer, J. Phys.: Condens. Matter 18, R667 (2006).

${ }^{40}$ D. O. Scanlon, A. Walsh, B. J. Morgan, M. Nolan, J. Fearon, and G. W. Watson, J. Phys. Chem. C 111, 7971 (2007).

${ }^{41}$ D. O. Scanlon, B. J. Morgan, and G. W. Watson, J. Chem. Phys. 131, 124703 (2009).

${ }^{42}$ H. Kawazoe, H. Yasakuwa, H. Hyodo, M. Kurita, H. Yanagi, and H. Hosono, Nature 389, 939 (1997).

${ }^{43}$ T. Thonhauser and K. M. Rabe, Phys. Rev. B 73, 212106 (2006).

${ }^{44}$ C. Franchini, G. Kresse, and R. Podloucky, Phys. Rev. Lett. 102, 256402 (2009).

${ }^{45}$ C. Franchini, A. Sanna, M. Marsman, and G. Kresse, Phys. Rev. B 81, 085213 (2010). 